\title{
Sweet grass protection against oxidative stress formation in the rat brain
}

\author{
Wojciech Luczaj • Iwona Jarocka-Karpowicz • \\ Katarzyna Bielawska $\cdot$ Elżbieta Skrzydlewska
}

Received: 13 April 2014 / Accepted: 4 August 2014 / Published online: 10 August 2014

(C) The Author(s) 2014. This article is published with open access at Springerlink.com

\begin{abstract}
The aims of this study were to investigate the influences of sweet grass on chronic ethanol-induced oxidative stress in the rat brain. Chronic ethanol intoxication decreased activities and antioxidant levels resulting in enhanced lipid peroxidation. Administration of sweet grass solution to ethanol-intoxicated rats partially normalized the activity activities of $\mathrm{Cu}, \mathrm{Zn}$-superoxide dismutase, catalase, glutathione peroxidase, and glutathione reductase, as well as levels of reduced glutathione and vitamins C, E, and A. Sweet grass also protected unsaturated fatty acids (arachidonic and docosahexaenoic) from oxidations and decreased levels of lipid peroxidation products: 4-hydroxynonenal, isoprostanes, and neuroprostanes. The present in vivo study confirms previous in vitro data demonstrating the bioactivity of sweet grass and suggests a possible role for sweet grass in human health protection from deleterious consequences associated with oxidative stress formation.
\end{abstract}

Keywords Coumarins $\cdot$ Oxidative stress $\cdot$ Ethanol $\cdot$ Lipid peroxidation $\cdot$ Antioxidants $\cdot$ Brain

\section{Introduction}

Cells in the nervous systems of animals, including humans, are vulnerable to oxidative damage from reactive oxygen species (ROS). Reasons for this vulnerability include a high concentration of readily oxidizable substrates (especially membrane phospholipid polyunsaturated fatty acids), a high ratio of membrane surface area to cytoplasmic volume, and an extended axonal morphology that is prone to peripheral injury

W. Łuczaj · I. Jarocka-Karpowicz · K. Bielawska •

E. Skrzydlewska $(\square)$

Medical University of Białystok, Białystok, Poland

e-mail: skrzydle@umb.edu.pl and low levels of protective antioxidant enzymes (e.g., catalase and glutathione [GSH] peroxidase [GSH-Px]) (Enciu et al. 2013; Kerman et al. 2005). A large amount of oxygen is also consumed in a relatively small tissue mass, and some brain regions have high nonheme iron concentrations (Shila et al. 2005).

Moreover, many brain mechanisms promote ROS generation (Joseph et al. 2005). For example, the oxidation of neurotransmitters is accompanied by ROS generation. Activated microglia, as the resident macrophages of the nervous system, can also participate in ROS generation. Thus, antioxidative defense is critically important in nervous tissue protection. If mild oxidative stress occurs, normal tissues often respond by bolstering antioxidant defense, although severe or persistent oxidative stress can cause cellular component injury, cellular degeneration, and, finally, brain cell death (Venkataraman et al. 2010).

Chronic ethanol consumption induces free-radicals production and consequent oxidative damage (Pronko et al. 2002; Koop 2006). Due to ethanol metabolism, the central nervous system (CNS) is influenced by substantial amounts of superoxide anion as the first ROS (Jung et al. 2008). Superoxide dismutase metabolizes superoxide anion into hydrogen peroxide, which can activate some neurotransmitters responsible for control such as dopamine (Adachi et al. 2001). Under the influence of iron (II) ions hydrogen peroxide is converted to the highly reactive hydroxyl radical, which can react with ethanol to form hydroxyethyl radicals (Sadrzadeh and Saffari 2004). In the CNS, the hydroxyethyl radical level is increased by isoenzyme CYP2E1 induction after ethanol intoxication (Sun and Sun 2001). Hydroxyethyl radicals react with acetaldehyde, an ethanol metabolite, resulting in increased CNS levels of acetyl radicals (Castro et al. 2009).

Potent antioxidants, especially those belonging to natural products, are under investigation for their potential ability to prevent oxidative stress and its consequences. One such 
potentially health-promoting plant is sweet grass (Hierochloë odorata), which belongs to the Graminacae grass family. Sweet grass is a strongly aromatic perennial grass normally found growing in the rich, moist soils of North America, Asia, and Europe. Although its chemical composition and biological properties have not been extensively investigated, it contains, among other compounds, coumarin and its derivatives 5,8-dihydroxycoumarin and 5-hydroxy-8-O- $\beta$-Dglucopyranosyl coumarin (Grigonis et al. 2005). Coumarin hydroxyl derivatives have been reported to have antioxidative and health-promoting properties (Kostova, 2006; Thuong et al. 2010; Li et al. 2013).

Previously Łuczaj et al. (2012) showed that a sweet grass beverage partially protects the liver against ethanol oxidative stress. Evidence of its antioxidative action is still growing, with the strong free radical scavenging and antioxidant properties of 5,8-dihydroxycoumarin confirmed in a recent study (Slapšyte et al. 2013). Therefore, the aim of this study was to investigate the influence of the consumption of a sweet grass beverage on oxidative stress formation and consequences in the brains of rats intoxicated with ethanol.

\section{Materials and methods}

Sweet grass extract used in the experiment contained coumarin $(312 \mathrm{mg} / \mathrm{l}), 5,8$-dihydroxycoumarin $(4,2 \mathrm{mg} / \mathrm{l})$ and 5-hydroxy-8-O- $\beta$-D-glucopyranosyl-benzopyranone $(3,1 \mathrm{mg} / \mathrm{l})$. The level of these compounds was determined using a gas chromatograph (Agilent Technologies) equipped with a triple quadrupole detector in the electron-impact ionization mode (GC System 7890A with GC/MS Triple Quad 7,000) and HP5MS capillary column $(30 \mathrm{~m} \times 0.25 \mathrm{~mm}$, ID $0.2 \mu \mathrm{m}$, Agilent Technologies). The system was equipped with autosampler (Agilent Technologies G4513A). Instrument control and data analysis were performed with Agilent GC software, MassHunter B.06.00. The column temperature was initially set at $50{ }^{\circ} \mathrm{C}$, and then raised at $10{ }^{\circ} \mathrm{C} / \mathrm{min}$ to $280{ }^{\circ} \mathrm{C}$ and maintained at this temperature for $10 \mathrm{~min}$. The split-splitless injector was used in split mode with a split ratio of 1:20. The carrier gas was helium at a flow rate of $1 \mathrm{~mL} / \mathrm{min}$. The injector and the transfer line were kept at $280{ }^{\circ} \mathrm{C}$, and the source temperature was set at $230{ }^{\circ} \mathrm{C}$. The MS unit was operated in scan mode $(50-500 \mathrm{~m} / \mathrm{z})$. The coumarin peak was identified by comparison of the retention time with the standard and its mass spectrum by using the National Institute of Standards and Technology Virtual Library (NIST) and the 5,8dihydroxycoumarin and the 5-hydroxy-8-O- $\beta$-Dglucopyranosyl-benzopyranone were identified by comparison with theirs mass spectrum. The concentration of coumarins in the sample was calculated using an external standard method $\left(1-500 \mu \mathrm{g} / \mathrm{ml}, \mathrm{R}^{2}=0,9982\right)$.

\section{Animals}

12 months old male Wistar rats were used for the experiment. They were housed in groups with free access to a granular standard diet and water and maintained under a normal lightdark cycle. The rats were weighed every week of experiment and changes in the weight of animals from different groups were not statistically significant. All experiments were approved by the Local Ethic Committee in Białystok (Poland) referring to Polish Act Protecting Animals of 1997.

The animals were divided into the following groups:

- Control group. Rats were treated intragastrically with $1.8 \mathrm{ml}$ of physiological saline every day for 4 weeks $(n=6)$.

- Sweet grass group. Rats received sweet grass water beverage (coumarin content $10 \mathrm{mg} / \mathrm{l}$ of water) ad libitum instead of water for 1 week. Next they were treated intragastrically with $1.8 \mathrm{ml}$ of physiological saline and received sweet grass water beverage ad libitum instead of water every day for 4 weeks $(n=6)$.

- Ethanol group. Rats were treated intragastrically with $1.8 \mathrm{ml}$ of ethanol in doses from 2.0 to $6.0 \mathrm{~g} / \mathrm{kg}$ b.w. every day for 4 weeks. The dose of ethanol was gradually increased by $0.5 \mathrm{~g} / \mathrm{kg}$ b.w. every 3 days $(n=6)$.

- Sweet grass and ethanol group. Rats received sweet grass water beverage ad libitum instead of water for 1 week. Next they were treated intragastrically with $1.8 \mathrm{ml}$ of ethanol in doses from 2.0 to $6.0 \mathrm{~g} / \mathrm{kg}$ b.w. and received sweet grass water beverage ad libitum instead of water every day for 4 weeks.

Preparation of tissue

After the above procedure, the rats were sacrified under ether anaesthesia (six animals in each group). Brain was removed quickly and placed in iced $0.15 \mathrm{M} \mathrm{NaCl}$ solution, washed with the same solution to remove blood cells, blotted on filter paper, weighed and homogenied in $9 \mathrm{ml}$ ice-cold $0.25 \mathrm{M}$ sucrose and $0.15 \mathrm{M} \mathrm{NaCl}$ with the addition of $6 \mu \mathrm{l} 250 \mathrm{mM}$ BHT (butylated hydroxytoluene) in ethanol to prevent the formation of new peroxides during the assay. Homogenization procedure was performed under standardized conditions; $10 \%$ homogenates were centrifuged at $10.000 \times \mathrm{g}$ for 15 min at $4{ }^{\circ} \mathrm{C}$, and the supernatant was kept on ice until assayed.

\section{Biochemical assays}

Superoxide dismutase (Cu,Zn-SOD - EC.1.15.1.1) activity was determined by the method of Misra and Fridovich (1972) as modified by Sykes et al. (1978), which measures the 
activity of cytosolic SOD. Mn-SOD of the brain mitochondria is known to be destroyed during this procedure. A standard curve for SOD activity was constructed using SOD from bovine erythrocytes (Sigma Biochemicals St. Louis MO). One unit of SOD was defined as the amount of the enzyme, which inhibits epinephrine oxidation to adrenochrome by $50 \%$. The enzyme specific activity was expressed in units per mg of protein.

Catalase (CAT - EC.1.11.1.9) activity was determined after 30 min preincubation of the postmitochondrial fraction of the brain homogenate with $1 \%$ Triton X-100 by measuring the decrease in absorbance of hydrogen peroxide at $240 \mathrm{~nm}$ (Aebi, 1984). The rates were determined at $25^{\circ} \mathrm{C}$ using $10 \mathrm{mM}$ hydrogen peroxide and the activity was expressed in units per $\mathrm{mg}$ of protein. One unit of CAT was defined as the amount of the enzyme required to catalyze $1 \mu$ mol $\mathrm{H}_{2} \mathrm{O}_{2}$ during $1 \mathrm{~min}$. The enzyme specific activity was expressed in units per mg of protein.

Glutathione peroxidase (GSH-Px - EC.1.11.1.6) activity was assessed in the brain spectrophotometrically using a technique based on Paglia and Valentine (1967). Applying this technique, GSH formation was assayed by measuring the conversion of nicotinamide adenine dinucleotide phosphate (NADPH) to NADP. The final concentration of GSH was $0.2 \mathrm{mM}$ and of $\mathrm{H}_{2} \mathrm{O}_{2}$ was $0.3 \mathrm{mM}$. The activity was expressed in universal units. One unit of activity was defined as the amount of enzyme catalyzing the oxidation of $1 \mu \mathrm{mol}$ of $\mathrm{NADPH} \min ^{-1}$, at $25^{\circ} \mathrm{C}$ and $\mathrm{pH}$ 7.4. The enzyme specific activity was expressed in units per $\mathrm{mg}$ of protein.

Glutathione reductase (GSSG-R - EC.1.6.4.2) activity was measured by the method of Mize and Langdon (1962) by monitoring the oxidation of nicotinamide adenine dinucleotide phosphate (NADPH) at $340 \mathrm{~nm}$. The reaction mixture contained $0.2 \mathrm{mM} \mathrm{KCl}, 1 \mathrm{mM}$ EDTA and $1 \mathrm{mM}$ oxidized GSH (GSSG) in 0.1 M potassium phosphate buffer, $\mathrm{pH}$ 7.1. The enzyme activity was expressed in units per $\mathrm{mg}$ of protein. One unit of GR oxidized $1 \mathrm{mmol}$ of NADPH/min at $25^{\circ} \mathrm{C}$ and $\mathrm{pH}$ 7.4. The enzyme specific activity was expressed in units per mg of protein.

GSH level was measured using the GSH/GSSG kit (Alpco Diagnostics, Salem, NH) according to kit instructions. The kit provides the HPLC method with fluorescence detection $\left(\lambda_{\mathrm{Ex}}=\right.$ $385 \mathrm{~nm}, \lambda_{\mathrm{Em}}=515 \mathrm{~nm}$; isocratic elution; flow rate: $1 \mathrm{ml} / \mathrm{min}$.).

The HPLC methods were used to determine the level of vitamin C (Ivanovic et al. 1999), vitamin A and E (De Leenher et al. 1979) and $\beta$-carotene (Elinder, 1992). To determine ascorbic acid $300 \mu \mathrm{l}$ of brain homogenate was mixed with an equal volume of metaphosphoric acid (100 g/l). Before analysis, the samples were centrifuged $(3,500 \times \mathrm{g}, 4 \mathrm{~min})$ to remove precipitated protein after which they were immediately assayed. The vitamin A and E were extracted from brain homogenate with hexane containing $0.025 \%$ butylated hydroxytoluene. The hexane phase was removed and dried with sodium sulfate, and $50 \mu \mathrm{l}$ of the hexane extract was injected on the column.

Free and phospholipid arachidonic acid (AA) and docosahexaenoic acid (DHA) were determined by gas chromatography (Christie 1993). Lipids components were isolated by Folch extraction using chloroform/methanol mixture $(2: 1$, $\mathrm{v} / \mathrm{v}$ ). Using TLC free fatty acids and total phospholipids were separated with the mobile phase heptane - diisopropyl ether acetic acid $(60: 40: 3, \mathrm{v} / \mathrm{v} / \mathrm{v})$. All lipid fractions were transmetylated to fatty acid methyl esters (FAMEs) with boron trifluoride in methanol reagent under nitrogen atmosphere without previous separation from the layer. The FAME's were analyzed by gas chromatography. The system consisted of a Perkin Elmer Clarus 500 gas chromatograph with FID (flame ionization detector) equipped with a Perkin Elmer AS XL autosampler. Separation of FAME was carried out on capillary column coated with Varian CP-Sil88 stationary phase.

Lipid peroxidation was estimated by measuring of 4hydroxynonenal (4-HNE), $\mathrm{F}_{2}$-isoprostanes (8-isoPGF $2 \alpha$ ) and total neuroprostanes level. 4-HNE was determined as a one of the fluorescent decahydroacridine derivatives formed in reaction with 1,3-cyclohexanodione. It was determined by HPLC with fluorescence detector with excitation at $380 \mathrm{~nm}$ and emission at $445 \mathrm{~nm}$ (Yoshino et al. 1986). Total brain $\mathrm{F}_{2}$ isoprostanes (8-isoPGF $2 \alpha$ ) and $\mathrm{A}_{4} / \mathrm{J}_{4}$-neuroprostanes (NPs) were quantified using modified high performance liquid chromatography mass spectrometry methods of Coolen and Fam respectively (Coolen et al. 2005 and Fam et al. 2002). 8isoPGF $2 \alpha$ as well as NPs were isolated using SPE method, after an alkaline hydrolysis step. All analysis were performed using an Agilent 1290 UPLC system interfaced with an Agilent 6,460 triple quadrupole mass spectrometer with electrospray ionization source (ESI). The system was equipped with autosampler (Agilent Technologies G4513A) and autosampler thermostat (Agilent Technologies G1330B). Instrument control and data analysis were performed with Agilent LC MassHunte software, rev. B.05.00. A Zorbax Eclipse Plus C18 $(2.1 \mathrm{~mm} \times 150 \mathrm{~mm}, 3.5 \mu \mathrm{m}$, Agilent, Santa Clara, CA) was employed. The separation was carried out with a linear gradient with water (adjusted to $\mathrm{pH} 5.7$ with acetic acid) and acetonitrile. In both cases tetradeuterated 8isoPGF ${ }_{2 \alpha}\left(8\right.$-isoPGF $\left.\mathrm{PF}_{2 \alpha}-\mathrm{d}_{4}\right)$ as an internal standard was used. 8 -isoPGF $2 \alpha$ was analyzed in negative-ion mode using multiple reaction monitoring (MRM). Transitions of the precursors to the product ions were as follows: $m / z 353.2 \rightarrow 193.1$ (for 8 isoPGF $2 \alpha$ ) and $357.2 \rightarrow 197.1$ (for 8 -isoPGF $2 \alpha-\mathrm{d}_{4}$ detection). The concentration of 8 -iso $\mathrm{PGF}_{2 \alpha}$ isomer in the samples was calculated using a calibration curve $\left(1-1,000 \mathrm{pg} / \mathrm{ml} \mathrm{R}^{2}=\right.$ $0,9,975)$. NPs were analyzed by selected ion monitoring (SIM) in the $\mathrm{m} / \mathrm{z} 357$, as a series of peaks that have molecular masses and retention times expected for NPs generated from the oxidation of DHA in vitro. DHA was oxidized in vitro using an iron/ADP/ascorbate mixture, as described 
elsewhere. ${ }^{31}$ The pattern of peaks representing A- and J-ring NPs was very similar to that obtained from the oxidation of DHA in vitro.

\section{Statistical analysis}

Data obtained in the current study are expressed as mean \pm SD. These data were analyzed by using standard statistical analyses, one-way analysis of variance (ANOVA) with Tukey test for multiple comparisons, to determine significant differences between different groups. A $p$ value of $<0.05$ was considered significant.

\section{Results}

The activity of antioxidant enzymes in the brain was altered by chronic ethanol intoxication (Table 1). After ethanol intoxication, it was showed a significant decrease in the brain activity of antioxidant enzymes such as superoxide dismutase (by about $60 \%$ ), GSH-Px (by about $24 \%$ ), GSSG-R (by about $37 \%$ ), and catalase (by about $37 \%$ ) compared to the control. After administration of sweet grass to ethanol intoxicated rats, activities of superoxide dismutase and GSSG-R were similar to the values observed in the brain of control animals. However activities of brain GSH-Px and catalase were significantly decreased (by approximately $10 \%$ and $21 \%$ ), compared to the control.

Ethanol intoxication also decreased the levels of nonenzymatic antioxidants, such as GSH (approximately $41 \%$ ), and vitamins $\mathrm{C}$, E, and A (approximately $24 \%, 17 \%$, and $38 \%$, respectively). Sweet grass solution partially prevented changes in the levels of these compounds. Vitamin E level in the brains of ethanol-intoxicated rats that received sweet grass solution remained similar to the control, while the levels of other nonenzymatic antioxidants were still significantly reduced compared to the control group.
Changes in the activities and levels of antioxidants after ethanol intoxication led to enhanced lipid peroxidation in the rat brain, as manifested by significant increases in the levels of lipid peroxidation products, such as 4-hydroxynonenal, and 8iso- $\mathrm{PGF}_{2 \alpha}$ (approximately $42 \%$ and $17 \%$, respectively) compared to the control group (Table 2). The most dramatic change was observed in the level of neuroprostanes (NPs). Increase in NPs after ethanol ingestion were more significant (almost two times higher) than 8 -isoPGF $2 \alpha$ which is a less specific marker of oxidative brain injury. Administration of sweet grass solution significantly decreased the levels of these markers, especially 8 -iso-PGF $2 \alpha$ and NPs (approximately $15 \%$ and $11 \%$ respectively). Chronic ethanol consumption influenced the levels of free and phospholipid fatty acids, particularly polyunsaturated fatty acids (PUFAs), corresponding with the increase in lipid peroxidation products observed in this study. Chronic ethanol consumption significantly decreased the levels of free arachidonic acid (AA) and docosahexaenoic acid (DHA) by about $12 \%$ and $19 \%$, respectively. Drinking the sweet grass solution significantly increased the DHA level (approximately $5 \%$ ), but did not cause considerable changes in the AA level (Fig. 1). Administration of sweet grass together with alcohol prevented the decrease in the AA and DHA levels, compared to the ethanol group. After ethanol administration, the phospholipid AA and DHA levels in the brain were decreased by about $8 \%$ and $6 \%$, respectively. Consumption of sweet grass solution alone caused approximately $10 \%$ increase in the DHA level, but did not cause significant changes in the AA level. Sweet grass given with alcohol increased the levels of AA and DHA (approximately $10 \%$ ) compared with the alcohol alone group.

\section{Discussion}

In the current study, we investigated whether administration of sweet grass ameliorated the oxidative damage caused to rat brain by ethanol intoxication, because despite the protection
Table 1 Antioxidant parameters in the brain of rats chronically intoxicated with ethanol and rats drinking sweet grass beverage and chronically intoxicated with ethanol

Data points represent mean $\pm \mathrm{SD}$; $n=6 ;{ }^{\mathrm{a}} p<0,05$ in comparison with control group; ${ }^{\mathrm{b}} p<0,05$ in comparison with sweet grass group; ${ }^{c} p<0,05$ in comparison with alcohol group)

\begin{tabular}{|c|c|c|c|c|}
\hline \multirow[t]{2}{*}{ Analyzed parameter } & \multicolumn{4}{|c|}{ Groups of rats } \\
\hline & Control & Sweet grass & Alcohol & $\begin{array}{l}\text { Alcohol } \\
+ \text { sweet grass }\end{array}$ \\
\hline $\mathrm{Cu}, \mathrm{Zn}-\mathrm{SOD}$ (U/mg protein) & $55.7 \pm 3.2$ & $53.4 \pm 3.8$ & $22.6 \pm 2.2^{\mathrm{ab}}$ & $34.7 \pm 2.9^{\mathrm{abc}}$ \\
\hline GSH-Px (U/mg protein) & $52.4 \pm 2.1$ & $47.3 \pm 2.5^{\mathrm{a}}$ & $39.8 \pm 3.5^{\mathrm{ab}}$ & $45.6 \pm 3.32^{\mathrm{ac}}$ \\
\hline GSSG-R (U/mg protein) & $3.51 \pm 0.17$ & $3.28 \pm 0.21$ & $2.20 \pm 0.15^{\mathrm{ab}}$ & $2.95 \pm 0.25^{\mathrm{abc}}$ \\
\hline CAT (U/mg protein) & $0.57 \pm 0.02$ & $0.45 \pm 0.02^{\mathrm{a}}$ & $0.36 \pm 0.03^{\mathrm{ab}}$ & $0.45 \pm 0.03^{\mathrm{ac}}$ \\
\hline $\mathrm{GSH}(\mu \mathrm{mol} / \mathrm{g}$ tissue $)$ & $0.95 \pm 0.06$ & $0.89 \pm 0.07$ & $0.56 \pm 0.04^{\mathrm{ab}}$ & $0.81 \pm 0.07^{\mathrm{ac}}$ \\
\hline Vitamin $C(\mu \mathrm{mol} / \mathrm{g}$ tissue $)$ & $2.34 \pm 0.16$ & $2.40 \pm 0.18$ & $1.77 \pm 0.13^{\mathrm{ab}}$ & $2.08 \pm 0.16^{\mathrm{abc}}$ \\
\hline Vitamin E (nmol/g tissue) & $24.32 \pm 1.33$ & $24.95 \pm 1.67$ & $20.12 \pm 1.51^{\mathrm{ab}}$ & $22.51 \pm 1.67^{\mathrm{bc}}$ \\
\hline Vitamin A (nmol/g tissue) & $0.42 \pm 0.02$ & $0.40 \pm 0.02$ & $0.26 \pm 0.02^{\mathrm{ab}}$ & $0.33 \pm 0.02^{\mathrm{abc}}$ \\
\hline
\end{tabular}


Table 2 Lipid peroxidation products (4-HNE, 8-isoPGF $2 \alpha$, and NPs) in the brain of rats chronically intoxicated with ethanol and rats drinking sweet grass beverage and chronically intoxicated with ethanol

\begin{tabular}{lllll}
\hline Analyzed parameter & Groups of rats & & & \\
\cline { 2 - 5 } & Control & Sweet grass & Alcohol & $\begin{array}{c}\text { Alcohol } \\
+ \text { sweet grass }\end{array}$ \\
\hline 4-HNE (nmol/g tissue) & & & $2.18 \pm 0.17^{\mathrm{ab}}$ & $1.84 \pm 0.14^{\mathrm{abc}}$ \\
8 -isoPGF $2 \alpha$ (ng/g tissue) & $1.54 \pm 0.09$ & $1.36 \pm 0.10^{\mathrm{a}}$ & $2.24 \pm 0.12^{\mathrm{ab}}$ & $2.17 \pm 0.11^{\mathrm{ab}}$ \\
NPs (ng/g tissue) & $1.91 \pm 0.10$ & $1.63 \pm 0.09^{\mathrm{a}}$ & $16.69 \pm 0.87^{\mathrm{ab}}$ & $13.34 \pm 0.69^{\mathrm{abc}}$ \\
\hline
\end{tabular}

Data points represent mean $\pm \mathrm{SD} ; n=6 ;\left({ }^{\mathrm{a}} p<0,05\right.$ in comparison with control group; ${ }^{\mathrm{b}} p<0,05$ in comparison with sweet grass group; ${ }^{\mathrm{c}} p<0,05$ in comparison with alcohol group)

offered by the blood-brain barrier, the CNS is subjected to ethanol-associated pathology as a result of ethanol metabolism-induced free radicals (Ponnappa and Rubin 2000, Gonthier et al. 2012). Ethanol oxidation by aldehyde dehydrogenase $(\mathrm{ADH})$ is accompanied by an increase in the reduced form of nicotinamide adenine dinucleotide (NADH) and a decrease in the $\mathrm{NAD}+\mathrm{NADH}$ ratio. This pathway results in the conversion of cytosolic xanthine dehydrogenase to xanthine oxidase, which is the enzyme responsible for generating superoxide radicals; NADH is also responsible for releasing iron (Fe) (II) ions from ferritin (Cederbaum et al. 2009). Free iron ions participate in the Haber-Weiss reaction, which ultimately leads to an increase in ROS generation (Nordmann et al. 1990).

In this study, we saw that the brains of ethanol-intoxicated rats show a significant decrease in the activity of antioxidant enzymes, including $\mathrm{Cu}, \mathrm{Zn}-\mathrm{SOD}$, which is the principal enzyme that brain cells use to defend themselves from superoxide anion and, consequently, from other ROS (Liu et al. 2007). The decrease in superoxide dismutase activity may even exacerbate neuronal cell damage and death, as shown previously (Venkataraman et al. 2010; Scolaro et al. 2012). The hydrogen peroxide generated as a result of $\mathrm{Cu}, \mathrm{Zn}-\mathrm{SOD}$ action is removed by GSH-Px and catalase, but ethanol intoxication causes a decrease in their activity.

Changes in the activities of the above enzymes may result from molecular modifications caused by ROS generated during ethanol metabolism. The most reactive hydroxyl radical, generated during other ROS transformations, may

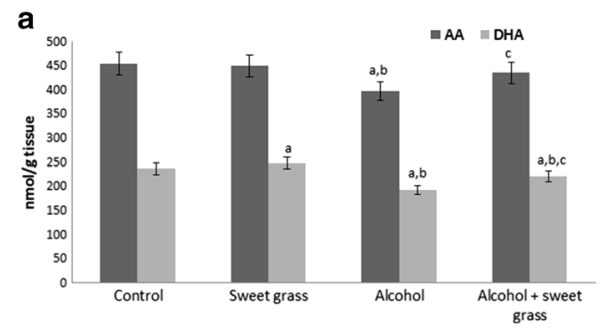

Fig. 1 The level of $\mathbf{a}$ free and $\mathbf{b}$ phospholipid arachidonic (AA) and docosahexaenoic acids (DHA) in the brain of rats chronically intoxicated with ethanol and rats drinking sweet grass beverage and chronically nonspecifically oxidize all protein amino acid residues. Those residues most sensitive to oxidative modifications are aromatic residues, as well as residues containing sulfur (cysteine and methionine) (Huggins et al. 1993; Berlett et al. 1996). Moreover, the molecules of enzymatic proteins may be modified by the 1-hydroxyethyl radical generated during ethanol metabolism, which can decrease the activity levels of catalase and other enzymes (Puntarulo and Cederbaum 1989).

Administration of the solution of a natural plant-sweet grass - to ethanol-intoxicated rats prevented changes in the activity of the antioxidative enzymes examined in this study. Sweet grass contains coumarin derivatives, specifically 5,8dihydroxycoumarin and 5-hydroxy-8-O- $\beta$-D-glucopyranosyl coumarin (Grigonis et al. 2005), which have proven antioxidative properties (Kostova 2006; Thuong et al. 2010; Slapšytė et al. 2013. Coumarin derivatives can inhibit the activity of xanthine oxidase (Nijveldt et al. 2001; Lin et al. 2008) and chelate transition metal ions (Kostova 2006), which may diminish the pro-oxidative action of ethanol. Hydroxyl derivatives of coumarins can also act as free radical scavengers, an action that is correlated with the number of hydroxyl groups in their structure (Lin et al. 2000; Huang et al. 2005). Thus, coumarins that possess hydroxyl groups are more potent free radical scavengers than their methoxy-substituted derivatives (Bilgin et al. 2011).

The rise in ROS levels, the disruption of the antioxidant system during ethanol intoxication, and the increased levels of free iron ions together lead to elevated oxidative stress and enhanced interactions between free radicals and lipids, which

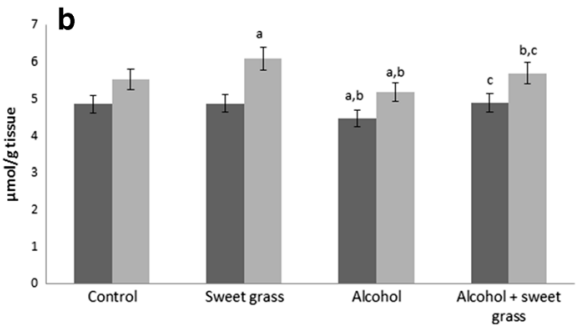

intoxicated with ethanol. Data points represent mean $\pm \mathrm{SD} ; n=6$; $\left({ }^{\mathrm{a}} p<0,05\right.$ in comparison with control group, ${ }^{\mathrm{b}} p<0,05$ in comparison with sweet grass group; ${ }^{\mathrm{c}} p<0,05$ in comparison with alcohol group) 
alter cellular structure and functions ( $\mathrm{Lu}$ and Cederbaum 2008). Oxidative lipid metabolism is regulated mainly by GSH-Px, which quickly metabolizes lipid peroxides to less toxic hydroxyl derivatives (Rosenblat and Aviram 1998). However, GSH-Px activity depends on its co-substrate GSH, whose concentration is diminished after ethanol intoxication, as observed here. Disturbances in the GSH-Px system lead to increased lipid peroxidation. Enhanced lipid peroxidation results in increased levels of small molecular aldehydes, such as 4-hydroxynonenal, as well as the prostaglandin derivatives isoprostanes (8-isoPGF ${ }_{2 \alpha}$ and NPs. The last two compounds are the most stable and specific markers of lipid peroxidation and are superior to other markers of oxidative damage. 8isoPGF ${ }_{2 \alpha}$ is formed mainly from peroxidation of $\mathrm{AA}$, which is abundant in all types of cells, whereas NPs are derived from DHA, which is particularly enriched in neurons (Montuschi et al. 2004; Niki 2014).

Phospholipids of brain membranes are particularly vulnerable to free radical action because they contain large amounts of unsaturated fatty acids. These fatty acids can be peroxidized, which modifies their composition and fluidizes the phospholipid bilayer, thereby disturbing the functional state of the brain cells (Rottkamp et al. 2000). In the present study, we observed decreased brain levels of free and phospholipid AAs and DHAs, as well as significant increases in the brain levels of 8 -isoPGF $2 \alpha$ and NPs after ethanol intoxication. The increase in the level of NPs was more significant than that of 8 -isoPGF $2 \alpha$ which is a less specific marker of oxidative brain injury.

Changes in the above markers had the same direction and similar intensification as those observed in the brain levels of the small molecular aldehydes MDA and 4-hydroxynonenal after alcohol consumption, as observed here and previously (Skrzydlewska et al. 2007; Cyuńczyk et al. 2012). Both aldehydes are highly reactive and may act as "secondary toxic messengers" of the primary free radical events. However, the present results demonstrated that sweet grass given to rats intoxicated with ethanol prevented the increase in lipid peroxidation, as earlier proven under in vitro conditions (Thuong et al. 2010). This action of sweet grass could be connected with the improvements in the levels of lipophilic antioxidants, such as vitamins $\mathrm{A}$ and $\mathrm{E}$, and decreases in ROS production, which prevent changes in membrane phospholipid disruption and protect biological membrane structure and functions, including membrane fluidity, as shown recently in vivo (Dobrzyńska et al. 2013).

Lipophilic antioxidants cooperate with GSH, but the concentration of this peptide is also diminished after ethanol intoxication. The GSH concentration depends on the levels of vitamins $\mathrm{E}$ and $\mathrm{C}$ because GSH is used, with the participation of vitamin $\mathrm{C}$, during regeneration of vitamin $\mathrm{E}$ from tocopherol radicals (Bunker 1992). Drinking sweet grass solution increased GSH and ascorbate levels and protected them from ethanol action. Coumarin and its hydroxyl derivatives have previously been shown to protect the kidney from reduced GSH levels, leading to increased GSH-Px activity and nonenzymatic antioxidant defenses (Lake et al. 2002; Khan et al. 2004). Sweet grass consumption has been suggested to enhance GSH and ascorbate antioxidant action and/or to act synergistically to facilitate radical transfer o GSH and ascorbate (Winterbourn 2008).

In conclusion, given that the metabolism of ethanol and coumarins is similar in rats and humans, the results obtained in this paper suggest that sweet grass may also protect human brain cells against the consequences of oxidative stress induced by ethanol intoxication. Moreover, substantial and growing evidence for the bioactivity of sweet grass in vivo demonstrates its potential role in protecting human health and preventing the deleterious consequences of brain diseases associated with oxidative stress.

Conflict of Interest The authors have no conflicts of interest to declare.

Open Access This article is distributed under the terms of the Creative Commons Attribution License which permits any use, distribution, and reproduction in any medium, provided the original author(s) and the source are credited.

\section{References}

Adachi YU, Watanabe K, Higuchi H, Satoh T, Vizi ES (2001) Oxygen inhalation enhances striatal dopamine metabolism and monoamineoxidase enzyme inhibition prevents it: a microdialysis study. Eur J Pharmacol 422:61-68

Aebi H (1984) Catalase in Vitro. Meth Enzymol 105:121-127

Berlett BS, Levine RL, Stadtman ER (1996) A comparison of the effects of ozone on the modification of amino acid residues in glutamine synthetase and bovine serum albumin. J Biol Chem 271:4177-4182

Bilgin HM, Atmaca M, Obay BD, Ozekinci S, Tasdemir E, Ketani A (2011) Protective effects of coumarin and coumarin derivatives against carbon tetrachloride-induced acute hepatotoxicity in rats. Exp Toxicol Pathol 63:325-330

Bunker VW (1992) Free radicals antioxidant and ageing. Med Lab Sci 49:299-312

Castro GD, Costantini MH, Castro JA (2009) Rat ventral prostate xanthine oxidase-mediated metabolism of acetaldehyde to acetyl radical. Hum Exp Toxicol 28:203-208

Cederbaum AI, Lu Y, Wu D (2009) Role of oxidative stress in alcoholinduced liver injury. Arch Toxicol 83:519-548

Christie WW (1993) Preparation of ester derivatives of fatty acids for chromatographic analysis. In: Christie WW (ed) Advances in Lipid Methodology - Two. Oily Press, Dundee, pp 69-111

Coolen SA, van Buuren B, Duchateau G, Upritchard J, Verhagen H (2005) Kinetics of biomarkers: biological and technical validity of isoprostanes in plasma. Amino Acids 29:429-436

Cyuńczyk M, Jarocka I, Hermanowicz J (2012) Protective effect of sweet grass and black berries beverages on ethanol-induced disturbances in brain fatty acids. Pro Health Sci 2:130-139

De Leenher A, De Bevere V, De Ruyter MG, Claeys AC (1979) Simultaneous determination of retinol and $\alpha$-tocopherol in human serum by HPLC. J Chromatogr 162:408-413 
Dobrzyńska I, Szachowicz-Petelska B, Skrzydlewska E, Figaszewski Z (2013) Effect of sweet grass (Hierochloe odorata) on the physicochemical properties of liver cell membranes from rats intoxicated with ethanol. Environ Toxicol Pharmacol 35:247-253

Elinder LSJ (1992) Antioxidant vitamin levels in plasma and low density lipoprotein of obese girls. Lipid Res 33:131-139

Enciu AM, Gherghiceanu M, Popescu BO (2013) Triggers and effectors of oxidative stress at blood-brain barrier level: relevance for brain ageing and neurodegeneration. Oxid Med Cell Longev doi: 10.1155/ 2013/297512

Fam SS, Murphey LJ, Terry ES, Zackert WE, Chen Y, Gao L, Pandalai S, Milne GL, Roberts LJ, Porter NA, Montine TJ, Morrow JD (2002) Formation of highly reactive A-ring and J-ring isoprostane-like compounds (A4/J4-neuroprostanes) in vivo from docosahexaenoic acid. J Biol Chem 277:36076-36084

Gonthier B, Allibe N, Cottet-Rousselle C, Lamarche F, Nuiry L, Barret L (2012) Specific conditions for resveratrol neuroprotection against ethanol-induced toxicity. J Toxicol. doi:10.1155/2012/973134

Grigonis D, Venskutonis PR, Sivik B, Sandahl M, Eskilsson CS (2005) Comparison of differebt extraction techniques for isolation of antioxidants from sweet grass (Hierochloe odorata). J Supercritical Fluids 33:223-233

Huang D, Ou B, Prior RL (2005) The chemistry behind antioxidant capacity assays. J Agric Food Chem 53:1841-1856

Huggins TG, Wells-Knecht MC, Detorie NA, Baynes JW, Thorpe SR (1993) Formation of o-tyrosine and dityrosine in proteins during radiolytic and metal-catalyzed oxidation. J Biol Chem 268:1234112347

Ivanovic D, Popovic A, Radulovic D, Medenica M (1999) Reversed phase ion-pair HPLC determination of some water-soluble vitamins in pharmaceuticals. J Pharm Biomed Anal 18:999-1004

Joseph JA, Shukitt-Hale B, Casadesus G, Fisher D (2005) Oxidative stress and inflammation in brain aging: nutritional considerations. Neurochem Res 30:927-935

Jung ME, Simpkins JW, Wilson AM, Downey HF, Mallet RT (2008) Intermittent hypoxia conditioning prevents behavioral deficit and brain oxidative stress in ethanol-withdrawn rats. J Appl Physiol 105:510-517

Kerman M, Cirak B, Ozguner MF, Dagtekin A, Sutcu R, Altuntas I, Delibas N (2005) Does melatonin protect or treat brain damage from traumatic oxidative stress? Exp Brain Res 163:406-410

Khan N, Sharma S, Sultana S (2004) Attenuation of potassium bromatedindeced nephrotoxicity by coumarin (12-benzopyrone) in Wistar rats: chemoprevention against free radical-mediated renal oxidative stress and tumor promotion response. Redox Rep 9:19-29

Koop DR (2006) Alcohol metabolism's damaging effects on the cell: a focus on reactive oxygen generation by the enzyme cytochrome P450 2E1. Alcohol Res Health 29:274-280

Kostova I (2006) Synthetic and natural coumarins as antioxidants. Mini Rev Med Chem 6:365-374

Lake BG, Evans JG, Chapuis F, Walters DG, Proce RJ (2002) Studies on the disposition metabolism and hepatotoxicity of coumarin in the rat and Syrian hamster. Food Chem Toxicol 40:809-823

Li W, Sun YN, Yan XT, Yang SY, Kim EJ, Kang HK, Kim YH (2013) Coumarins and lignans from Zanthoxylum schinifolium and their anticancer activities. J Agric Food Chem 61:10730-10740

Lin HC, Tsai SH, Chen CS, Chang YC, Lee CM, Lai ZY, Lin CM (2008) Structure-activity relationship of counarin derivatives on xanthine oxidase-inhibiting and free radical-scavenging activities. Biochem Pharmacol 75:1416-1425

Lin WL, Wang CJ, Tsai YY, Liu CL, Hwang JM, Tseng TH (2000) Inhibitory effect of esculetin on oxidative damage induced by $\mathrm{t}-$ butyl hydroperoxide in rat liver. Arch Toxicol 74:467-472

Liu D, Bao F, Wen J, Liu J (2007) Mutation of superoxide dismutase elevates reactive species: comparison of nitration and oxidation of proteins in different brain regions of transgenic mice with amyotrophic lateral sclerosis. Neuroscience 146:255-264
Lu Y, Cederbaum AI (2008) CYP2E1 and oxidative liver injury by alcohol. Free Radic Biol Med 44:723-738

Łuczaj W, Stankiewicz-Kranc A, Milewska E, Roszkowska-Jakimiec W, Skrzydlewska E (2012) Effect of sweet grass extract against oxidative stress in rat liver and serum. Food Chem Toxicol 50:135-140

Misra HP, Fridovich I (1972) The role of superoxide anion in the autooxidation of epinephrine and a simple assay for superoxide dismutase. J Biol Chem 247:3170-3175

Mize CE, Langdon RG (1962) Hepatic glutathione reductase Purification and general kinetic properties. J Biol Chem 237:1589-1595

Montuschi P, Barnes PJ, Roberts LJ 2nd (2004) Isoprostanes: markers and mediators of oxidative stress. FASEB J 18:1791-1800

Nijveldt RJ, van Nood E, van Hoorn DEC, Boelens PG, van Norren K, Paul AM, van Leeuwen PAM (2001) Flavonoids: a review of probable mechanisms of action and potential applications. Am J Clinical Nutrition 74:418-425

Niki E (2014) Biomarkers of lipid peroxidation in clinical material Biochim Biophys Acta 1840:809-817

Nordmann R, Ribière C, Rouach H (1990) Ethanol-induced lipid peroxidation and oxidative stress in extrahepatic tissues. Alcohol Alcohol 25:231-237

Paglia DE, Valentine WN (1967) Studies on the quantitative and qualitative characterization of erytrocyte glutathione peroxidase. J Lab Clin Med 70:158-169

Ponnappa BC, Rubin E (2000) Modeling alcohol's effects on organs in animal models. Alcohol Res Health 24:93-104

Pronko P, Bardina L, Satanovskaya V, Kuzmich A, Zimatkin S (2002) Effect of chronic alcohol consumption on the ethanol- and acetaldehyde-metabolizing systems in the rat gastrointestinal tract. Alcohol Alcohol 37:229-235

Puntarulo LA, Cederbaum AI (1989) Chemiluminescence from acetaldehyde oxidation by xanthine oxidase involves generation of and interactions with hydroxyl radicals. Alcohol Clin Exp Res 13:84-90

Rosenblat M, Aviram M (1998) Macrophage glutathione content and glutathione peroxidase activity are inversely related to cellmediated oxidation of LDL: in vitro and in vivo studies. Free Radic Biol Med 24:305-317

Rottkamp CA, Nunomura A, Raina AK, Sayre LM, Perry G, Smith MA (2000) Oxidative stress antioxidant and Alzheimer disease. Alzheimer Dis Assoc Disord 14:62-66

Sadrzadeh SMH, Saffari Y (2004) Iron and Brain Disorders. Am J Clin Pathol 121:64-70

Scolaro B, Delwing-de Lima D, da Cruz JG, Delwing-Dal Magro D (2012) Mate tea prevents oxidative stress in the blood and hippocampus of rats with acute or chronic ethanol administration. Oxid Med Cell Longev doi: 101155/2012/314758

Shila S, Kokilavani V, Subathra M, Panneerselvam C (2005) Brain regional responses in antioxidant system to alpha-lipoic acid in arsenic intoxicated rat. Toxicology 210:25-36

Skrzydlewska E, Ostrowska J, Łuczaj W, Augustyniak A (2007) Green and black tea in brain protection. In: Qureshi GA, Parvez SH (eds) Oxidative stress and neurodegenerative disorders. Elsevier Science, Amsterdam, pp 581-605

Slapšytė G, Dedonytė V, Lazutka JR, Mierauskienė J, Morkūnas V, Kazernavičiūtè R, Pukalskas A, Venskutonis PR (2013) Evaluation of the biological activity of naturally occurring 5,8dihydroxycoumarin. Molecules 18:4419-4436

Sun AY, Sun GY (2001) Ethanol and oxidative mechanisms in the brain. J Biomed Sci 8:37-43

Sykes A, McCormac FX, O'Brien J (1978) Prelimirary study of the superoxide dismutase content of some human tumors. Cancer Res 38:2759-2762

Thuong PT, Hung TM, Ngoc TM, Ha T, Min BS, Kwack SJ, Kang TS, Choi JS, Bae K (2010) Antioxidant activities of coumarins from Korean medicinal plants and their structure-activity relationships. Phytother Res 24:101-106 
Venkataraman P, Selvakumar K, Krishnamoorthy G, Muthusami S, Rameshkumar R, Prakash S, Arunakaran J (2010) Effect of melatonin on PCB (Aroclor 1254) induced neuronal damage and changes in $\mathrm{Cu} / \mathrm{Zn}$ superoxide dismutase and glutathione peroxidase-4 mRNA expression in cerebral cortex cerebellum and hippocampus of adult rats. Neurosci Res 66:189-197
Winterbourn CC (2008) Reconciling the chemistry and biology of reactive oxygen species. Nat Chem Biol 4:278-286

Yoshino K, Matsuura T, Sano M, Saito S, Tomita I (1986) Fluorometric liquid chromatographic determination of aliphatic aldehydes arising from lipid peroxides. Chem Pharm Bull 34:1694-1700 